\title{
O espectador frente à nudez corporal na cena teatral curitibana
}

\section{The spectator in front a body nudity in curitiba's theatrical scene}

Sara Dobginski de Moraes $^{1}$

Robson Rosseto ${ }^{2}$ 


\section{Resumo}

Este artigo tem como foco a análise da recepção teatral de espetáculos que contêm corpos nus em cena. Para tanto, a presença da nudez em protestos sociais e no teatro brasileiro, assim como a nudez como tabu social e os fatores histórico-culturais associados a isso, são alguns dos pontos apresentados no estudo. Tendo como base a recepção teatral, a pesquisa de campo delimitou-se à cidade de Curitiba/PR. A partir de questionários entregues a 25 espectadores de peças com nudez em cena e de entrevista realizada com o diretor Cesar Almeida, este estudo examina as diferentes opiniões e percepções com relação à presença de corpus nus em cenas teatrais.

Palavras-Chave: Nudez em cena; Espetáculo Teatral; Recepção Teatral.

\section{Abstract}

This article focuses on the analysis of theatrical reception of dramatic scenes that contain naked bodies on stage. Therefore, the presence of nudity in social protests and in Brazilian theater, as well the nudity as taboo social and the historical-cultural factors associated with it, are some of the points presented in this study. Based on the theatrical reception, the field research was delimited to the city of Curitiba/PR. From the 25 questionnaires distributed for spectators of theatrical performances with nudity scene and from the interview with director Cesar Almeida, this study examines the different opinions and perceptions relative the presence of naked corpus in theatrical scenes.

Keywords: Nudity in theatrical scene; Theater; Theatrical reception.

ISSN: $1808-3129$

\footnotetext{
${ }^{1}$ Graduada no Curso de Bacharelado em Artes Cênicas e graduanda no Curso de Licenciatura em Teatro da Universidade Estadual do Paraná - bolsista pela Fundação Araucária. Brasil. saradobginski@hotmail.com

${ }^{2}$ Doutorando em Artes da Cena pela Universidade Estadual de Campinas/UNICAMP, Mestre em Teatro pela Universidade Estadual de Santa Catarina/UDESC e docente da Universidade Estadual do Paraná/UNESPAR, campus de Curitiba II - Faculdade de Artes do Paraná. rossetorobson@gmail.com
} 


\section{Introdução}

Com o objetivo de investigar a nudez corporal no teatro, cabe apresentar um breve histórico dos corpos nus nas produções teatrais brasileiras, para uma maior compreensão de determinadas proposições cênicas e sua receptividade até a atualidade. Em seguida, o estudo apresenta uma pesquisa de campo sobre o corpo nu na cena teatral, na cidade de Curitiba, com base nas percepções do espectador e do encenador.

A partir dos anos de 1960, a nudez corporal começou a aparecer em relatos de protestos brasileiros, período esse reconhecido por mudanças, com grandes transformações na sociedade e na forma de produção, o que se refletiu tanto nas atitudes políticas quanto nas manifestações culturais (BARRETO, 2012). Segundo Bortoloti (2008), nos anos de 1980 a nudez passou a ser extremamente utilizada como forma de protesto social.

Os registros de cenas teatrais com atores nus datam a partir dos anos de 1960, quando, como Sousa (2011) aponta, o movimento da contracultura ${ }^{1}$ expandiu no país. Algumas das peças que continham cenas com nudez ficaram conhecidas no teatro nacional como revolucionárias, sendo elas: O Rei da Vela, texto de Oswald de Andrade, encenada em 1967 pelo teatro Oficina - primeira vez que o nu apareceu no teatro Oficina - (SOUSA, 2011) e Macunaíma, texto de Mário de Andrade, encenada pela primeira vez em 1978 pelo Grupo Pau-Brasil, o espetáculo foi considerado um "divisor de águas" do teatro brasileiro (ARAÚJO, 2011). Cabe destacar,

[...] o grupo Oficina teve uma passagem marcante no teatro brasileiro, se não pela qualidade do espetáculo pelo menos devido ao impacto causado com a encenação, pela primeira vez, de um texto de Oswald de Andrade [...]. José Celso Martinez Corrêa se propôs a realizar um espetáculo de grande importância. Se não obteve aplauso da crítica, pelo menos alcançou um sucesso de choque, atraindo o interesse dos meios artísticos e do público (OLIVEIRA, 1999, p. 129).

Os discursos e os espetáculos dos atores e diretores do grupo Oficina têm como objetivo provocar um atentado, ofendendo as leis ou a moral, assim como alegado pelo projeto da contracultura (SOUSA, 2011). Dessa maneira, José Celso Martinez Corrêa (um dos fundadores do grupo Oficina) afirma: "Então, um dos itens é: Vá direto ao tabu. Não perca tempo, porque é lá que está a riqueza, se você for ao tabu, lá tem petróleo, lá jorra, entende?" (2004).

No Rio de Janeiro, em janeiro de 1967, estreou com grande alarde a peça Roda Viva, de Chico Buarque de Holanda, a qual continha cenas de nudismo, não agradando alguns segmentos da sociedade. No final da encenação dessa produção, no Teatro Galpão em São Paulo em 1968, vinte homens armados espancaram atores, músicos e técnicos e depredaram o teatro. Em Porto Alegre sequestraram a atriz Elizabeth Gas-

\footnotetext{
1 "No século XX, com o Movimento de 68 promovido (em 1968) por estudantes e jovens professores em diversos países do mundo (principalmente França e Estados Unidos), contra o autoritarismo, o capitalismo e a cultura oficial promovida pelos Estados capitalistas e comunistas, houve o movimento hippie, o fortalecimento da ecologia, do feminismo, do pacifismo, e do rock n'roll e de novos estilos de música e de arte em geral. [...] No mesmo Movimento de 68 houve também uma grande valorização do estudo de culturas diferentes, principalmente as orientais e as indígenas, e a busca de novas formas de vida em sociedade, geralmente em busca de uma melhor integração com a natureza (inclusive a natureza humana, o que desembocou em uma grande valorização da psicologia e da psicanálise) - tudo isso ficou conhecido como o movimento da Contracultura. [...] o movimento acabou semeando aqui uma nova estética, principalmente na música: a estética tropicalista.". (O MOVIMENTO de 68 e a contracultura, 2014).
} 
per, no momento em que participava do espetáculo. Por fim, a peça acabou proibida pela censura² (OLIVEIRA, 1999).

É importante destacar que em variadas culturas o corpo nu é um tabu e enfrenta proibições de distintas naturezas, em função do contexto histórico culturalmente apreendido. Por isso, quando a nudez é levada ao público torna-se muitas vezes motivo de desavença e de intensa repercussão social. Os artigos 233 e 234 do código penal brasileiro apresentam regras no qual condenam a nudez em ambiente público, tendo por objetivo resguardar o pudor em situações que possam constranger as pessoas, configurando crime de ato obsceno, com punição de até um ano de detenção. No entanto, esse crime se efetiva somente quando o agente tem a vontade de provocar um atentado ao pudor público e, nas peças teatrais (o inciso II incorre sobre a atividade teatral), a presença de corpos nus é entendida juridicamente como parte integrante do espetáculo, absolvendo o agente da acusação de dolo. Portanto, a nudez é condenada criminalmente quando combinada à sexualidade e intencionando-se dano à moral por meio desta (SOUSA, 2011).

De acordo com Miranda (2009), por exemplo, na cidade de Belém, Luís Otávio Barata causou polêmica em camadas conservadoras ao colocar atores nus em cena. A nudez ainda é um tabu na cidade, uma vez que a sociedade paraense está muito ligada a padrões de certo e errado, à cultura estética midiática e a preconceitos obtidos pela educação tradicional europeia. Em 1990, a peça Em nome do amor, de Barata, causou grande polêmica e, em uma remontagem realizada em 2001 (Paixão Barata \& Madalenas), o mesmo fervor se estabeleceu, no qual um grupo de Deputados paraenses apresentou uma Nota de Repúdio ao espetáculo:

[...] quanto mais exagerado ou repetitivo o uso grotesco da homossexualidade e do nu, mais próximos ficam da normalidade, o jogo com os tabus faz a imagem do pênis se tornar banal de tão repetitiva na cena. [...] a obscenidade mostrada na cena causava um desarranjo do sistema social, perturbando os princípios e os códigos cívicos que, na maioria das vezes, acabava sendo censurada ou protestada. Lutando contra uma sociedade que sempre vestiu os homens [...] Barata despiu seu pensamento, através dos corpos nus, que falam e reagem por eles mesmos (MIRANDA, 2009, p.148).

Com relação à nudez no teatro curitibano, Costa (1990) relata que em 1927 é recepcionada na capital a Companhia de Revistas Feéricas do Teatro Glória (Tro-lóló) do Rio de Janeiro, a qual apresentou o nu artístico nas cenas de sua peça. A nudez foi proposta sem que a ousadia da encenação ultrapassasse o limite do aceitável para os padrões da época, de tal maneira, para evitar polêmicas, os diretores da peça informaram no Diário da Tarde:

O estonteante nu artístico será pela formosa e perfeita bailarina francesa Sônia Botgen, auxiliada por 2 das mais lindas "girls" do Tró-ló-tó [...] Pede-nos a Empresa, tornemos público, que o referido quadro é dedicado às Exmas. Famílias Curitibanas e nada tem de ofensivo à moral, como maléficamente vem sendo propalado, pois ele representa uma pura e verdadeira manifestação de arte, elegancia e beleza. $\mathrm{O}$ Tró-ló-ló seria incapaz de apresentar coisas ofensivas ao público de elite que lhe tem sabido aplaudir (DIÁRIO DA TARDE apud COSTA, 1990, p. 23-24).

${ }^{2}$ Ao citar a censura, cabe lembrar: o Regime Militar Brasileiro instaurou-se no ano de 1964 e teve seu fim em 1985. 
A empolgação do público com o nu foi tanta que os jornais se referiam às lotações completas e ao entusiasmo da plateia, levando a companhia a reprisar a nudez artística (COSTA, 1990). No entanto, décadas depois, na 8ª edição do Festival de Teatro de Curitiba, em 1999, a reação do público à nudez no palco parece ter sido oposta: a peça Bent - O canto preso foi apresentada, na qual "cenas fortes envolvendo nudismo, sexo e escatológica [sic] são oferecidas sem pudores ao público. Uma montagem forte e moderna que incomodou bastante" (BASTOS apud ALMEIDA, 2002, p. 226).

Os exemplos expostos apontam que algumas propostas teatrais com nus em cena foram aceitas pelo público, enquanto outras foram consideradas incômodas pelos espectadores. Os diferentes aspectos políticos e sociais de cada época tendem a impulsionar percepções diferenciadas do espectador, produzindo reações diversas. Para um melhor entendimento da relação cena e plateia frente à nudez, adentro no estudo da recepção teatral.

Segundo Desgranges $(2002,2008)$, a relação entre o modo de atuação e o espectador tem sofrido consideráveis modificações desde o surgimento do teatro moderno (século XIX - século XX) até a atualidade. Essas mudanças ocorrem em simultaneidade às transformações surgidas nas propostas dos artistas e no contexto social dos diferentes períodos, uma vez que a relação do teatro com o espectador está relacionada com a especificidade de cada época no modo de ver o mundo.

No decorrer do século XVIII, o drama burguês propunha ao espectador um forte envolvimento emocional com as tramas apresentadas, ele era convidado a viver com o herói/protagonista e imergir no universo ficcional da peça - a atividade estética estava assimilada a um ato de empatia. Já no fim do século XIX e início do XX, surgiu o drama moderno em oposição ao drama burguês e, nesse novo caso, o espectador recebia um convite crítico-reflexivo, no qual, apesar de continuar a se identificar com o protagonista, as interrupções da lógica dramática (efetuadas pelos recursos cênicos narrativos épicos) faziam o espectador retornar à própria consciência e ao seu lugar de observador (DESGRANGES, 2002, 2008).

Assim como o drama moderno questionou o drama burguês, a arte teatral atual fez o mesmo. O teatro contemporâneo pretendeu levar ao extremo a atitude proposta pelo drama moderno, de modo que, ao invés de o espectador imergir da obra ficcional, o objeto artístico passa a invadir o espectador, não agindo mais por empatia, mas sim, por uma significação associada às próprias experiências do observador.

Cada manifestação artística estabelece relações particulares no campo da recepção e no contato com o público, devido ao próprio caráter histórico atrelado à recepção teatral. As diferentes formas da nudez apresentada em uma peça teatral e a maneira como ela é recebida podem variar intensamente em distintas regiões do território brasileiro, por razões sociais, estéticas ou até mesmo por marketing. É possível verificar tal questão no artigo A nudez no teatro contemporâneo: Estratégia de mercado ou recurso estético, de Marcello Gabbay e Michele Miranda (2009), no qual são analisados dois casos específicos de nudez na cena teatral, referentes a duas peças, uma do Rio de Janeiro e outra de Belém. No primeiro caso, a presença do nu de uma atriz reconhecida nacionalmente foi utilizada como marketing para atrair pú- 
blico para a peça, fato refletido nas críticas sobre o espetáculo, as quais apresentaram textos elogiando a forma física da celebridade. No segundo caso, a nudez foi utilizada como construção política e estética do teatro local, mas, mesmo sendo empregada como instrumento ritualístico, gerou grande polêmica nas camadas sociais conservadoras.

Tendo como base o contexto histórico e a localidade geográfica como fatores que influenciam na recepção de um espetáculo teatral, delimitei para a pesquisa de campo a cidade de Curitiba. O objetivo é apresentar uma reflexão sobre como proposições de determinadas peças teatrais com atores nus em cena são recepcionadas na atualidade.

\section{Pesquisa de campo}

Este estudo contou com uma pesquisa de campo para realizar a análise atual do espectador frente à nudez corporal na cena teatral curitibana. As técnicas de investigação foram o questionário e a entrevista: foram questionados 25 espectadores, profissionais e não profissionais das artes cênicas, que assistiram peças com nudez em algum momento de suas vidas, e entrevistado 1 diretor que exerce sua profissão na cidade de Curitiba e utiliza atores nus em grande parte de seus espetáculos.

$\mathrm{Na}$ elaboração do questionário foram priorizadas 7 questões: estruturada, semiestruturada e não estruturada. Os participantes da pesquisa, realizada nos meses de abril e maio de 2014 em Curitiba, responderam de forma anônima, apenas as idades e formações ou profissões foram reveladas. Dos indivíduos entrevistados, $76 \%$ possuem profissões ou formações fora da área do teatro (professores, estudantes de medicina veterinária e letras, servidor público, analista de sistema, aposentados, entre outros) e $24 \%$ são atores, diretores e estudantes de artes cênicas. Resultado das primeiras perguntas do questionário:

Gráfico 01. Idade dos questionados

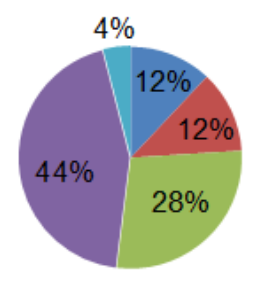

Gráfico 02. Motivaçöes dos questionados para ir ao tea tro

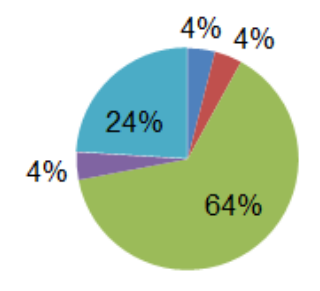

= Entre 50-59 anos

- Entre 40-49 anos

= Entre 30-39 anos

- Entre 20-29 anos

= 19 anos

Escolares/estudantis
- Familiares
m Culturais
- Outro
- Mais de uma altemativa
ass inalada


Gráfico 03. Frequência, em média, que o indivíduo assiste a peças teatrais

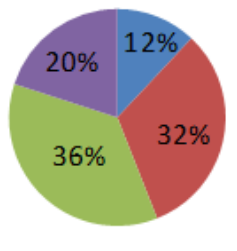
- Uma peça por ano
- Uma peça por semestre
- Uma peça por mês
- Outro

Ao analisar os dados das figuras 01,02 e 03, é possível constatar que mais da metade dos questionados afirma ir ao teatro por motivações culturais e a maioria deles assiste a peças teatrais com alta frequência, pelo menos uma vez por mês. Contudo, ao comparar essas informações com os dados de outra pesquisa, produzida no ano de 2013 pela Secretaria-Geral da Presidência da República, notifica-se o contrário, evidenciando que a população brasileira vai ao teatro com pouquíssima frequência: a investigação foi operada com 1.100 jovens, de 15 a 29 anos de idade, e mostrou que apenas $4 \%$ deles escolhem ir ao teatro em momentos de lazer, a maioria (61\%) prefere ir a parques e praças. "Em relação à frequência em atividade de lazer e cultura pelo menos uma vez na vida, os dados são igualmente alarmantes: [...] 65\% jamais foram ao teatro [...]" (MOURA, 2014).

A comparação entre essas pesquisas pode ser realizada, pois, ainda que a investigação da Secretaria-Geral tenha se limitado ao público de 15 a 29 anos e a investigação do presente estudo tenha compreendido idades até 59 anos, os sujeitos entre 19 e 29 anos se mantiveram como a maioria (48\%) nesta análise sobre a nudez em cena. Conquanto, outra pesquisa realizada em 2013 pelo Serviço Social do Comércio - SESC (2014), contando com 2.400 entrevistados em 25 estados brasileiros, não se limitou a margens de idade e obteve o mesmo resultado: $61 \%$ das pessoas nunca haviam assistido a uma peça teatral e apenas $1 \%$ delas dedicava-se a esse tipo de atividade nos fins de semana.

O elemento capaz de ter influenciado na diferença entre a pesquisa deste estudo e as pesquisas descritas acima, corresponde aos $24 \%$ de indivíduos profissionais ou estudantes de teatro que responderam às questões, pois é esperado que esses frequentem o espaço teatral com maior intensidade. Além disso, alguns entrevistados revelaram já terem sido estudantes da área, afirmando assistir a peças, em média, uma vez por mês. Também cabe considerar o fato de os questionários terem sido entregues apenas a pessoas que já haviam assistido a peças com nudez em cena, inevitavelmente todas elas já haviam comparecido ao teatro pelo menos uma vez na vida. Sendo assim, segundo as pesquisas da Secretaria-Geral e do SESC, os 25 indivíduos

Gráfico 04. Sobre recordar-se da primeira peça com atores nus assistida.
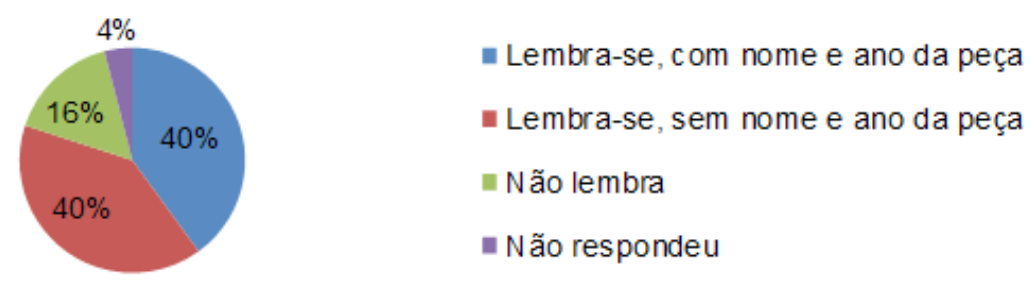
questionados sobre o nu em cena fazem parte de menos da metade da população brasileira que já se dirigiu ao teatro.

Tratando especificamente do assunto de corpos despidos na cena teatral, a próxima pergunta do questionário procurou entender sobre a quantidade de peças com atores nus assistida pelo pesquisado: $84 \%$ informaram ter assistido a poucas peças com nudez e $16 \%$ a muitas peças. Em seguida, questionou-se se recordavam da primeira peça com nudez presenciada:

Um dado considerável pode ser observado no gráfico 04: a maior parte dos questionados (80\%) lembra-se da primeira peça assistida com atores nus, dentre esses, metade recorda inclusive o nome e/ou o ano da peça - exemplos citados: "Oh Calcutá (1990)", “Luis Antonio-Gabriela (2013)", "Satyricon Delírio (2013)", "A bicicleta do condenado (2012)", “Álbum de Família (1994), "não me lembro o nome, mas foi no 'guairinha'" (2006), "17x Nelson" (2012)", "1999", "2004", dentre outros. Grande parte dos indivíduos assistiu à primeira peça com presença de atores nus no século XXI, no entanto, há dois entrevistados que assistiram pela primeira vez uma nudez em cena no século passado e, ainda assim, lembram-se do nome e ano da peça.

O questionário apresentou também duas questões elaboradas de forma não estruturada, com o intuito de focalizar se houve alguma nudez em cena marcante para o entrevistado e com a intenção de conhecer a percepção dele sobre a utilização do nu no teatro. Acerca de uma cena impactante pela presença da nudez, algumas das respostas foram: "Lembro que a primeira peça com cenas de nudez que assisti me marcou, pois eu não esperava ver aquela cena, não sabia que haveria nudez.", "Sim. Foi muito bonito, eu chorei, me emocionei e gostei muito.", "Não, pois assisti apenas uma peça com atores nus, nada que tenha marcado.", "[...] foi interessante ver o quanto o corpo nu, que é o corpo natural, está tão distanciado da nossa vida e ao mesmo tempo não.", "Sim, nesse caso específico não tinha o porquê da nudez daquela forma apresentada.", "Especificamente não. A presença da nudez, quando 'adequada', na maioria das vezes me passa despercebida.", "Sim, a da primeira vez que assisti." e "Sim, [...] uma atriz transexual (corpo feminino) que mostrou seu pênis na peça e a plateia ficou impressionada. Todos esperavam ver uma vagina [...]." Do mesmo modo, destaco a descrição de cena de um dos entrevistados:

[...] Quando abriu a cortina tinha um homem nu de costas para a plateia, um corpo lindo escultural, havia pouca luz no palco e assim ele dançou maravilhosamente. A plateia ficou quase em choque porque era um musical, sobre samba e ninguém esperava aquilo. Ele ficou o tempo todo de costas dançou e saiu do palco, foi lindo.

Um número considerável de entrevistados relatou que a peça com nudez mais chocante correspondeu à primeira peça com nudez que viram na vida, dentre esses, alguns relataram que não estavam preparados ou não estavam esperando ver o nu em cena. Talvez essa sensação de "despreparo" se deve à configuração histórica social, o tabu em torno da nudez.

Outros questionados, ao serem perguntados sobre como percebem a utilização do nu em cena, salientaram o quanto a nudez às vezes é utilizada apenas para 
"chamar atenção", exemplos: "Percebo de duas formas: uma apelativa ou de expurgo (sexual, pessoal), que poderia ser substituída por outros signos [...]", "Acredito que é válida desde que tenha um propósito bem claro. Não é algo atual estar nu em cena, não é mais uma atitude revolucionária, já foi.", "Acredito que ela deve ocorrer desde que vá de acordo com o contexto da peça, pois percebo que, às vezes, a nudez em cena acontece sem sentido [...]. Nesse último caso, penso que essas atitudes afastam o espectador do ator ou da peça em si.", "Muitas vezes é desnecessária e apelativa. Na nossa sociedade é um termo muito delicado e deve ser adotado só quando for de extrema relevância, sem banalizações." e "Quando a nudez em cena tem o único objetivo de tentar chocar o público não a percebo como parte da unidade do espetáculo, mas como algo incoerente e desnecessário.". Destaco ainda as respostas de uma atriz e de uma bailarina, respectivamente:

Na maioria das vezes desnecessária. Sinto que banalizaram a nudez por quererem se expressar, ter essa "liberdade", ou tentar chamar a atenção de alguma forma que não a cena em si. A maioria das peças que fui ver, a nudez não condizia com o texto e proposta, era uma nudez gratuita.

Nem sempre a vejo como necessária, muitas vezes ouvi o discurso de fazer peças com nudez para experimentar algo novo. Não sei até que ponto, nós espectadores precisamos ser cobaias para essas experiências. Por outro lado, assisti a uma peça sobre feminismo, nela as mulheres apareciam sem soutien, achei bem pertinente e no contexto absolutamente plausível.

Em tais descrições, é possível evidenciar: quase todas as pessoas questionadas acreditam que a nudez, para ser bem utilizada, deve ter uma proposta clara e não deve ser apresentada de forma banal ou sem intenção. Similarmente, as citações expostas acima revelam que duas artistas curitibanas possuem, de certo modo, a mesma opinião de outros entrevistados, os quais são em sua maioria profissionais advindos de áreas distintas.

Por lei, é obrigatório anunciar a classificação indicativa de uma peça teatral (indicando os limites de idade a que a peça não se recomenda), para que o público possa se informar sobre os aspectos e temas a serem abordados no espetáculo. A lei no 8.069, de 13 de julho de 1990, trata sobre a classificação indicativa de diversões e espetáculos públicos. No parágrafo único do artigo 74, consta: “Os responsáveis pelas diversões e espetáculos públicos deverão afixar, em lugar visível e de fácil acesso, à entrada do local de exibição, informação destacada sobre a natureza do espetáculo e a faixa etária especificada no certificado de classificação." (BRASIL, 1990).

Há inclusive um Guia Prático para a classificação indicativa, o qual apresenta pontos que podem ser atenuantes ou agravantes sobre determinada indicação de classificação. A nudez corporal aparece nesse manual como um dos critérios das tendências de indicação, desta forma suas descrições operacionais a subdividem em faixas etárias a que não se recomendam. Para uma classificação 'Livre', por exemplo, são admitidos conteúdos que apresentem nudez artística/científica/cultural exposta de maneira não erótica - como um documentário, cujo conteúdo mostra a realidade de uma tribo indígena com pessoas nuas. Por outro lado, quando o conteúdo apresenta erotização ou obscenidade, a classificação indicativa passa a ser de 14 anos de 
idade e, quando a obra constituir sexo explícito, a classificação é de 18 anos (CLASSIFICAÇÃO indicativa: guia prático, 2014).

No questionário, quando indagado sobre concordar ou não com o dever de divulgar e exibir a classificação indicativa de peças teatrais, quase todos os sujeitos (96\%) responderam concordar com essa proposição. Todavia, o 4\% refere-se a uma entrevistada, estudante de artes cênicas, que marcou as duas alternativas (concordo e não concordo), justificando: "Não acredito que apenas a presença da nudez seja motivo para existir classificação indicativa, mas sim como a nudez será utilizada no espetáculo. Se for apenas um corpo nu em cena, sem qualquer insinuação sexual, não vejo a necessidade de haver classificação.".

É notável a entrevistada citar a necessidade de diferenciar as diversas formas de se mostrar a nudez para então classificá-las, pois é justamente essa a sugestão do artigo 74. No entanto, apesar de a estudante não concordar com a necessidade de divulgar a classificação em determinadas situações, a lei obriga que isso ocorra, ainda quando a classificação é 'Livre'. Aparentemente a lei tenta prevenir o público sobre o conteúdo presente, por exemplo, em uma peça teatral, sendo esse um dos aspectos levantados por alguns indivíduos questionados, os quais alegaram terem sido pegos de surpresa e despreparados ao verem a nudez corporal no palco.

Para a entrevista foram elaboradas 11 questões, abordando o assunto da utilização de corpos nus no teatro. O intuito de realizar uma entrevista com um diretor atuante em Curitiba, que já tivesse colocado a nudez em cena, é o de relacionar as percepções dele ao utilizar esse recurso com as percepções expostas pelos espectadores abordados. A entrevista ocorreu com o diretor Cesar Almeida ${ }^{3}$, de 51 anos, no dia 9 de maio de 2014, em Curitiba/PR.

Para iniciar a entrevista, foi questionado se Almeida possui algum público específico para o qual destina suas peças. Ele revelou trabalhar em grande parte de suas obras com a questão LGBT $^{4}$. A primeira vez que Almeida colocou nudez em cena foi entre os anos de 1989 e 1990 e o principal motivo pelo qual o fez foi por acreditar na existência de um apelo atávico do ser humano pelo nu e por acreditar na impossibilidade de viver a existência de uma maneira plena se os desejos não forem satisfeitos, complementando:

É uma questão da necessidade que o ser humano tem de apreciar o corpo, de ver o corpo. Então acho que a beleza da apreciação do nu é um desejo que extrapola a nossa racionalidade e isso precisa ser satisfeito [...]. Se formos ver a história da arte toda, ela é feita em nome da religião, mas ela está trabalhando o que? Ela está trabalhando o erotismo, na verdade. Eu acredito que o erótico sempre esteve presente no desejo mais íntimo do ser humano. Só que, infelizmente, o discurso ainda precisa ser velado. Demoramos muito tempo pra conseguir assumir a questão da nudez, de assumir que nós gostamos de ver o nu.

\footnotetext{
${ }^{3}$ A formação de Almeida é terceiro grau incompleto - chegou a cursar Arquitetura, mas desistiu do curso -, cursou Artes Cênicas em Curitiba na época em que o curso ainda não era ensino superior, ele conta as lutas enfrentadas para torná-lo terceiro grau e, quando se tornou, teria que fazer mais quatro anos para concluí-lo: "Acho que a arte independe dessa questão de formação, então como a minha intenção não era ser um acadêmico, e sim, seguir a minha direção e a minha autoria teatral, eu falei 'não estou necessitando disso assim, não'”, diz Almeida. Ele veio de Londrina a Curitiba para ter a possibilidade de viver de teatro, pois acredita ser difícil viver profissionalmente de teatro em outra cidade do Paraná. Almeida atua como diretor teatral desde 1982 , ano no qual começou a fazer o curso em Curitiba e quando escreveu seu primeiro texto e fez sua primeira direção.

${ }^{4}$ Sigla de Lésbicas, Gays, Bissexuais, Travestis, Transexuais e Transgêneros.
} 
É possível relacionar essas respostas de Cesar Almeida com as de 2 professores que responderam aos questionários - na questão sobre qual é a percepção do indivíduo acerca da utilização da nudez na cena teatral -, sendo as respostas: "Uma força [sic] de chamar atenção ao corpo, quebrar paradigmas, desconstruir o pecado da nudez..." e "Percebo como uma linguagem que problematiza questões ligadas ao corpo e gênero/sexualidade. Não considero vulgar, para mim é semelhante à pinturas/fotografias de nu artístico." Observa-se que a intenção de Almeida ao pôr o nu em cena corresponde à percepção que ambos questionados possuem.

Em continuidade à entrevista, foi perguntado com qual frequência ele costuma utilizar atores nus em cena, no qual respondeu ser com constância, afirmando que hoje em dia não consegue mais dissociar a nudez com a arte, sendo esse um dos ingredientes necessários para o seu teatro. Ao longo da entrevista, foi questionado sobre suas intenções ao colocar o nu em cena: "Ninguém sai imune à nudez em cena, ou você rejeita por alguma questão de uma educação religiosa, repressora ou você sente que a sua liberdade está sendo aprovada ou está sendo compartilhada com o outro", declarando acreditar que a nudez não deixa margem para se ficar impassível perante a obra de arte, sendo altamente eficaz como linguagem artística. A resposta de Almeida reflete-se nos dados obtidos na presente pesquisa, uma vez que dentre os 25 espectadores abordados, 80\% lembram-se da primeira peça com nudez assistida. Além disso, todos os indivíduos apresentaram alguma opinião com relação à utilização da nudez no teatro, nenhum relatou estar imparcial ao tema.

Voltando à entrevista, Almeida revelou já ter passado por várias situações embaraçosas pelo impacto causado por suas peças no público e/ou na crítica, enfatizando o ocorrido em 1999 com a peça Querelle. Nesse espetáculo a nudez era escancarada e colocada em cena de uma forma "muito aberta", o que resultou em tentativas de censura e repreensão do trabalho. Porém, o encenador ressaltou: "Esse espetáculo, na verdade, era um sucesso de público, todas as casas lotadas, mas a contrapartida era essa reação muito violenta da instituição, do poder institucional pra cima da obra [...]". Talvez essa percepção do diretor tenha sido a mesma percepção de uma atriz e assistente social que respondeu ao questionário, pois, ao escrever sobre alguma nudez em cena causadora de impacto, ela relatou sobre determinada peça de Cesar Almeida e comentou sobre a "coragem" do diretor para tratar do assunto no período, dando a entender que a peça causou certo impacto nos espectadores ou na sociedade: "Sim, no espetáculo O Evangelho GLS de São Sebastião de Cesar Almeida. Fiquei impactada com a estética maravilhosa do espetáculo e com a coragem do autor de expressar-se sobre tema tão delicado para a época, embora não faça tanto tempo assim" (2005).

Quanto à classificação indicativa, Almeida afirma concordar com o dever de exibi-la, pois, da mesma maneira que se alerta algumas pessoas sobre o conteúdo da peça, também se atrai outras, as quais vão ao espetáculo exatamente pela presença do nu. Ele afirma colocar a classificação indicativa em suas obras, mas revela situações em que o público levantou e saiu no meio da apresentação, explicando: 
espectador, agora, quando você mexe na questão realmente sexual da coisa, aí é complicado, as pessoas ainda têm muito pudor de ver a sua sexualidade retratada em cena. Então isto é algo que realmente tem um impacto maior: a questão da nudez aliada à sexualidade, à pornografia [...].

Por fim, Cesar Almeida comenta sobre a utilização da nudez em cena especificamente na cidade de Curitiba e revela não ser fácil colocar o nu corporal no teatro nesta cidade, em razão de acreditar que é uma região extremamente conservadora. Além disso, afirma ser um dos poucos a fazer isso na capital paranaense.

Pessoas não profissionais das artes cênicas foram predominantes neste estudo, sendo que grande parte dos indivíduos entrevistados se lembram do primeiro nu teatral presenciado. A maioria dos questionados têm em sua memória alguma cena teatral marcante com presença de nudez corporal e, entre esses, alguns acreditam na nudez utilizada apenas quando necessária e condizente com o contexto da obra e, outros, acreditam que o nu está banalizado e não provoca o mesmo choque de outrora.

Em meio a diferentes relatos e opiniões, se mostra semelhante nesta investigação que a nudez corporal em cena causa algum tipo de impacto na maior parte das pessoas que a presenciam, de forma a ser, como Cesar Almeida acredita, uma ferramenta que impossibilita a imparcialidade do espectador perante a obra artística apresentada.

\section{Referências}

ALMEIDA, G. P. de. Palco iluminado: o Festival de Teatro de Curitiba. 193 f. Dissertação (Mestrado em Letras) - Universidade Federal do Paraná, Curitiba, 2002.

ARAÚJO, C. B. C. Macunaíma: da rapsódia ao palco. Literatura em Debate, Rio Grande do Sul, v.5, n.8, p. 257-270, jan.-jul., 2011.

BARRETO, N. M. C. A Nudez como arma política: um estudo comparativo do nu feminino na mídia. In: Congresso de ciências da comunicação na região sudeste, 17., 2012, Ouro Preto/MG. Resumos... Disponível em: <http://www.intercom.org.br/papers/regionais/sudeste2012/resumos/R3315081.pdf. Acesso em 21/09/2012.

BORTOLOTI, M. Nudez: fenômeno onipresente. Veja, São Paulo, n. 49, dez. 2008. 200 p. Edição 2090.

BRASIL. Decreto-lei n. 8.069, de 13 de julho de 1990. Capítulo II. Seção I. Diário Oficial da República Federativa do Brasil. Disponível em: <http://www.planalto. gov.br/ccivil_03/leis/l8069.htm>. Acesso em 02/05/2014.

CLASSIFICAÇÃO INDICATIVA: GUIA PRÁTICO. Disponível em: < http://pfdc.pgr. 
mpf.mp.br/atuacao-e-conteudos-de-apoio/publicacoes/comunicacao/guia -pratico-da-classificacao-indicativa>, Acesso em 02/05/2014.

COSTA, M. M. da. Curitiba, teatro e euforia, 1927. Revista Letras, Curitiba, v.39, 1990.

DESGRANGES, F. O espectador e a contemporaneidade: perspectivas pedagógicas. Sala Preta. 2002, v. 2, p. 221-228

DESGRANGES, F. Teatralidade tátil: alterações no ato do espectador. Sala Preta. 2008 , v. 8, p. 11-19.

ENTREVISTA COM ZÉ CELSO, Teatro Oficina - parte 2. DW. 2004. Disponível em:<http://www.dw.de/entrevista-com-z\%C3\%A9-celso-teatro-oficina-parte-2/a-1219931-2>. Acesso em 02/04/2014.

GABBAY, M. e MIRANDA, M. C. de. A nudez no teatro contemporâneo: estratégia de mercado ou recurso estético. In: Encontro ESPM de comunicação e marketing nudez. 3, 2009. São Paulo - SP. Anais... Disponível em <http://caepmblog.espm.br/EVENTOS/Illencontro/PDF/A\%20NUDEZ\%20NO\%20TEATRO\%20 CONTEMPORANEO.pdf> Acesso em: 21/01/2014.

MIRANDA, M. C. de. Luís Otávio Barata: por uma cena aberta e política no Pará. Revista Ensaio Geral, Belém, v.1, n.2, jul/dez 2009.

MOURA, R. M. Lazer para jovem é gratuito, em casa ou ao ar livre. Estadão - São Paulo. Disponível em: <http://sao-paulo.estadao.com.br/noticias/geral\%2clazer-para-jovem-e-gratuito-em-casa-ou-ao-ar-livre-imp-\%2c1156131>. Acesso em 20/07/2014.

O MOVIMENTO DE 68 E A CONTRACULTURA. Disponível em: < http://projetoquem.com.br/index.php?lang=pt-br\&menu=2\&submenu=9>. Acesso em 01/06/2014.

OLIVEIRA, P. R. C. de. Aspectos do teatro brasileiro. Curitiba, PR: Juruá, 2002.

SOUSA, M. A. R. de. A nudez em cena: teatro Oficina, o espelho mágico e o nu artístico. Revista Habitus: revista eletrônica dos alunos de graduação em Ciências Sociais - IFCS/UFRJ, Rio de Janeiro, v. 9, n. 1, p. 07-23, ago. 2011. 